\title{
A rare case of severe hypertriglyceridemia induced pancreatitis in pregnancy
}

\author{
Poonam Kashyap $^{1 *}$, Sudha Prasad ${ }^{1}$, Chandra Bhushan Singh ${ }^{2}$
}

\begin{abstract}
${ }^{1}$ Department of Obstetrics and Gynecology, Maulana Azad Medical College and Lok Nayak Hospital, Delhi, India ${ }^{2}$ Department of Surgery, Maulana Azad Medical College and Lok Nayak Hospital, Delhi, India
\end{abstract}

Received: 17 September 2017

Accepted: 27 October 2017

\author{
*Correspondence: \\ Dr. Poonam Kashyap, \\ E-mail: drpoonamkashyap@gmail.com
}

Copyright: (c) the author(s), publisher and licensee Medip Academy. This is an open-access article distributed under the terms of the Creative Commons Attribution Non-Commercial License, which permits unrestricted non-commercial use, distribution, and reproduction in any medium, provided the original work is properly cited.

\begin{abstract}
Acute pancreatitis is caused by various causes such as Gall stone disease, alcoholism, drug abuse but rarely caused by severe hypertriglyceridemia. It typically presents as acute or recurrent pancreatitis. The hypertriglyceridemia can be gestation induced or familial. The family history of the pregnant women needs to be taken in detail. The serum triglyceride levels in the range of 1000 to $2000 \mathrm{mg} / \mathrm{dl}$ in patients with type I, III, IV and V hyperlipoproteinemia (Friedrickson's classification) is the identifiable risk factor. The clinical course of hypertriglyceridemia induced pancreatitis is similar to other causes. We hereby report a case of 21 -year-old lady G3P1L0A1 with 37 weeks of pregnancy without any family history of hypertriglyceridemia and but with history of recurrent episodes of acute pancreatitis.
\end{abstract}

Keywords: Hypertriglyceridemia, Lipemia, Pancreatitis

\section{INTRODUCTION}

Acute pancreatitis is a common condition with various possible etiologies, gall stones and alcohol being the most common. ${ }^{1}$ Other causes could be metabolic, structural, and iatrogenic causes which accounts for $20-25 \%$ of the cases. $^{2}$ After gall stone and alcohol, hyperlipidemia in the form of hypertriglyceridemia or chylomicronemia, is one of the well-accepted underlying causes of acute pancreatitis in $7 \%$ of the cases. ${ }^{3}$ Hypertriglyceridemia can be primary in less than $5 \%$ of the cases, due to genetic causes and more often secondary to other causes like diabetes, obesity, pregnancy, excess carbohydrate intake, hypothyroidism, alcohol, hepatitis, sepsis, renal failure, and drugs like estrogen, glucocorticoids, $\beta$ blocker, bile acid binding resins, thiazide, tamoxifen cyclosporine protease inhibitors, and isotretinoin. ${ }^{4}$ Most patients can be effectively treated with the existing drug therapy. Heparin and insulin have a role to play in the treatment. ${ }^{5}$ Other novel modalities include plasma exchange and lipid aphaeresis. $^{6}$ Here we report a case of female with recurrent pancreatitis with hypertriglyceridemia and discussing the pathogenesis and management and the importance of early recognition of cause of pancreatitis.

\section{CASE REPORT}

A case of G3 P1 L0A1, 37 weeks with history of previous LSCS and recurrent acute pancreatitis. She had first episode of acute pancreatitis during her first pregnancy 3 years back in 2014 at 34 weeks period of gestation. Patient had intrauterine death of fetus and LSCS was done for transverse lie. Patient conceived spontaneously after 1 year. She had missed abortion and D\&C was done. During her hospital stay, she was diagnosed with pancreatic pseudocyst with splenic vein thrombosis. Patient was also diagnosed with cholelethiasis for which laparoscopic cholecystectomy was done. Third episode of pancreatitis occurred during her third pregnancy after 8 months of last episode. 
At 35 weeks of period of gestation, patient had episode of acute pancreatitis. She presented with acute pain abdomen in casualty. She also had history of fever for one day. Her pulse was 100/min.

BP was $110 / 70 \mathrm{~mm}$ of $\mathrm{Hg}$. Her blood investigations showed leukocytosis (20000). Platelet count 1.5 L. Her blood sugar was high $(160 \mathrm{mg} \%)$. In LFT serum bilirubin $0.2 \mathrm{mg} \%$. SGOT 89, SGPT 45. Her B. urea $34 \mathrm{mg} \%$, S. creatinine $0.7 \mathrm{mg} \%$. Serum amylase 126, serum lipase 227. S. Ca 8.0. Parathormone levels were in normal range. Ultrasound abdomen showed atrophic pancreas with mild ascites with necrotic collection in lesser sac and grade 1 fatty liver. No peripancreatic collection was seen and surrounding fat showed increased echogenicity. Patient was managed conservatively with intravenous fluids and narcotics for pain relief and antibiotics. She was advised diabetic diet and followed up in antenatal OPD. At 38 weeks period of gestation, patient was admitted with complaints of labour pains. Her routine investigations were done which were normal. Her serum amylase and lipase were also in normal range. Her Prothrombin time was done which was deranged because of lipemic sample. Her lipid profile was done which was found deranged. Total Cholesterol was $413 \mathrm{mg} / \mathrm{dl}$, Triglyceride $1537 \mathrm{mg} / \mathrm{dl}$, HDL $55 \mathrm{mg} / \mathrm{dl}$, LDL $37 \mathrm{mg} /$ dl. The patient had full term vaginal delivery and baby of $2.6 \mathrm{~kg}$ was born with APGAR score of 9,9,9. At this time, a diagnosis of hypertriglyceridemia induced acute pancreatitis was considered. She was also started on fibrate derivatives as well as low fat, restricted calorie, clear liquid diet. Our patient was advised to restrict fat to $10-15 \%$ of total energy intake (about $15-20 \mathrm{~g} /$ day) with reduction in saturated fats and unsaturated and trans fats. ${ }^{7}$

\section{DISCUSSION}

The association between acute pancreatitis and hyperlipidemia is well known, both as a precipitant and as an epiphenomenon. Hypertriglyceridemia may occur in pregnancy due to normal physiological changes leading to abnormalities in lipid metabolism. This patient had no previous family of lipid abnormality. Her serum triglyceride levels were not done in previous two episodes of acute pancreatitis and thus missing important cause. Clinical recognition of this association is extremely important, because therapy with diet and lipidlowering agents may prevent development of pancreatitis. Such a severe hypertriglyceridemia is usually seen in patients with familial chylomicronemia syndromes where hypertriglyceridemia is exacerbated by the pregnancy, leading to fatal complications such as acute pancreatitis. ${ }^{8}$ Chylomicrons are triglyceride-rich lipoprotein particles. They are present in the circulation when triglycerides are $>10 \mathrm{mmol} / \mathrm{L}(900 \mathrm{mg} / \mathrm{dl})$. These are large enough to occlude the pancreatic capillaries, leading to ischemia and subsequent acinar structural alteration, and also a release of pancreatic lipase. Enhanced lipolysis leads to an increased concentration of free fatty acids, which results in the release of inflammatory mediators and free radicals culminating in inflammation, edema, and necrosis. $^{9}$

Chylomicrons are the products of dietary fat absorption. Therefore, abstinence from eating fat after pancreatitis helps rapid metabolism of these triglyceride rich chylomicrons. Other measures include weight reduction, reducing intake of fat, calories and refined food.

Fibrates are the mainstay of therapy. They reduce plasma triglyceride levels by $50 \%$ and raise HDL cholesterol by $20 \%$. They also decrease VLDL secretion and also increase lipolysis of plasma triglyceride. Other therapies which are useful are Statins and Omega-3-fatty acids. Statins reduce the cholesterol by inhibiting hydroxylmethylglutaryl CoA reductase, thereby reducing coronary heart disease end points in type 2 diabetes. Omega-3-fatty acids (eicosapentanoic and docosahexanoic acid) reduce plasma triglycerides by $20 \%$ when used in combination with other triglyceridelowering therapies. ${ }^{10}$ Antioxidant therapies (Selenium, $\beta$ carotene, vitamin $\mathrm{C}, \alpha$-tocopherol) have also been used in the reduction of recurrent pancreatitis episodes in patients with markedly hypertriglyceridemia after medical therapy. They act by giving protection from free radicalinduced acinar damage. The coexistent medical conditions such as diabetes should prompt further workup. $^{11}$ Other novel modalities include plasma exchange and lipid aphaeresis, insulin and heparin, and lipoprotein lipase gene therapy. ${ }^{12}$ When plasmapheresis is unavailable or contraindicated, intravenous infusion of regular insulin and 5\% dextrose can be used. Blood sugar is maintained between 150 and $200 \mathrm{mg} / \mathrm{dL}$ during this therapy. Insulin and heparin infusions act by stimulating LPL activity, which then removes triglycerides from the plasma.

\section{CONCLUSION}

It is important to diagnose hypertriglyceridemia induced pancreatitis in this modern era as it has become more common than believed. Early recognition is valuable as treatment with lipid lowering agents may prevent further episodes of pancreatitis preventing maternal and foetal mortality and morbidity.

\section{Funding: No funding sources Conflict of interest: None declared Ethical approval: Not required}

\section{REFERENCES}

1. Gursoy A, Kulaksizoglu M, Sahin M, Ertugrul DT, Ozer F, Tutuncu NB, et al. Severe hypertriglyceridemia-induced pancreatitis during pregnancy, J National Med Assoc. 2006;98(4):655-7.

2. Athyros VG, Giouleme OI, Nikolaidis NL, Vasiliadis TV, Bouloukos VI, Kontopoulos AG, et al. Longterm follow-up of patients with acute 
hypertriglyceridemia-induced pancreatitis. J Clin Gastroenterol. 2002;34(4):472-5.

3. Lykkesfeldt G, Bock JE, Pedersen FD, Meinertz H, Faergeman O. Excessive hypertriglyceridemia and pancreatitis in pregnancy. Association with deficiency of lipoprotein lipase. Acta Obstetricia et Gynecologica Scandinavica. 1981;60(1):79-82.

4. Ramin KD, Ramin SM, Richey SD, Cunningham FG. Acute pancreatitis in pregnancy. Am J Obstet Gynecol. 1995;173(1):187-91.

5. Alagözlü $H$, Cindoruk $M$, Karakan $T$, Ünal $S$. Heparin and insulin in the treatment of hypertriglyceridemia-induced severe acute pancreatitis. Digestive Diseases Sciences. 2006;51(5):931-3.

6. Routy JP, Smith GHR, Blank DW, Gilfix BM, Plasmapheresis in the treatment of an acute pancreatitis due to protease inhibitor-induced hypertriglyceridemia. J Clinical Apheresis. 2001;16(3):157-9.

7. Takaishi K, Miyoshi J, Matsumura T, Honda R, Ohba T, Katabuchi H. Hypertriglyceridemic acute pancreatitis during pregnancy: prevention with diet therapy and $\omega-3$ fatty acids in the following pregnancy. Nutrition. 2009;25(11-12):1094-7.

8. de Chalain TMB, Michell WL, Berger GMB, Hyperlipidemia, pregnancy and pancreatitis. Surg Gynecol Obstet. 1988;167(6):469-73.
9. Mizushfrna T, Ochi K, Matsumura N, Ichimura M, Ishibashi T, Tsuboi $\mathrm{K}$, et al. Prevention of hyperlipidemic acute pancreatitis during pregnancy with medium-chain triglyceride nutritional support. Int J Pancreatol. 1998;23(3):187-92.

10. Altun D, Eren G, Cukurova Z, Herg"unsel O, Yasar L. An alternative treatment in hypertriglyceridemiainduced acute pancreatitis in pregnancy: plasmapheresis. J Anaesthesiol Clin Pharmacol. 2012;28(2):252-4.

11. Cahalane AM, Smith MJ, Ryan J, Maguire D, Acute pancreatitis secondary to gestational hypertriglyceridaemia. Case Reports in Medicine. 2012:627890.

12. Henzen C, R*ock M, Schnieper C, Heer K. Heparin and insulin in the treatment of acute hypertriglyceridaemia induced pancreatitis. Swiss Medical Weekly. 1999;129(35):1242-8.

Cite this article as: Kashyap P, Prasad S, Singh CB. A rare case of severe hypertriglyceridemia induced pancreatitis in pregnancy. Int J Reprod Contracept Obstet Gynecol. 2017;6:5625-7. 